\section{Stagnant waters flow at last at Sizewell B power station}

\section{London}

BRITAIN's nuclear power programme, stagnant for almost a decade, finally resumed its course last week with the start of construction on the Sizewell B pressurized water reactor (PWR) station in Suffolk. Triumphantly declaring "the waiting is now over" before clambering on a large crane, Lord Marshall, the chairman of CEGB, inaugurated work on a diaphragm wall, $1,200 \mathrm{~m}$ long and $50 \mathrm{~m}$ deep. The wall will allow the site to be drained without affecting ecologically important wetlands nearby or the Sizewell A gas-cooled reactor station.

CEGB started looking for a site for its first PWRs in 1977. Preliminary hearings on a planning application were held in 1982, but a full-scale public inquiry was launched in January 1983, and lasted until March 1985.

Layfield's eight-volume report, recommending approval of the project, appeared last January, and the then Secretary of State for Energy, Mr Peter Walker, rubber-stamped the decision in March.

By the time Walker gave the go-ahead, CEGB's bill had reached $£ 200$ million. So far, contracts worth $£ 650$ million have been placed, with a further 60 contract packages remaining to be awarded, to bring the total cost of the project to $£ 1,600$ million at current prices. CEGB intends that the station will be generating 1,175 MW by 1994 , and that five or six similar stations across the country will follow, with the first application, for a station at Hinkley Point in Somerset, to be subwould like to see. mitted before the end of this year.

But the PWR programme may need to be revised in view of the government's manifesto pledge to sell the electricity industry to private investors, detailed plans for which are expected by the end of the year. The returns on individual power

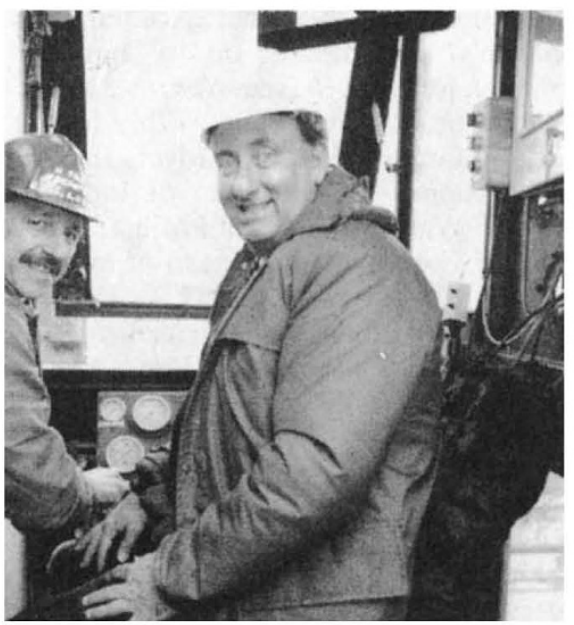

"I am determined that Sizewell $B$ will be built to time and cost". Lord Marshall at the new site.

stations similar to Sizewell B could be too risky to attract investors. If the CEGB were to be privatized as a single entity, the risks could be spread, but the sale would not give rise to the competition in power generation that many in the government

Because CEGB did not expect such a prolonged debate over Sizewell B, no new nuclear power stations had been ordered since 1978 . This meant that permission

\section{Solar reactor to be gamma-ray observatory}

Paris

AN experimental French solar energy plant, abandoned since July 1986 because it used more electricity than it produced, is to be turned into a gamma-ray observatory. Based at Thémis in the eastern Pyrenees, this innovative project, called ASGAT (Astronomie Gamma à Thémis), is the result of a collaboration between the Institute for Fundamental Research of the Commissariat à l'Energie Atomique (CEA), which developed the solar plant, and the Institute for Sciences of the Universe (INSU), part of France's leading science research body, the Centre Nationale de la Recherche Scientifique (CNRS). When completed in spring 1988, the observatory will be the largest of its kind.

By using the focusing mechanism and mirror mountings of the Thémis plant, about 60 per cent of construction costs of a new observatory will be saved. The conversion essentially involves replacing the existing 200 plane mirrors by seven $7-\mathrm{m}$ diameter parabolic mirrors. With the aid of photomultipliers, these mirrors will pick up 'Cerenkov light' produced by gammaray photons arriving from deep space, which generate very high-energy particles in the upper atmosphere. The surface area of the Thémis mirrors will be greater than that of all other gamma observatories put together, according to Philippe Goret, the project's director. This will enable the source of the high-energy gamma rays to be located with a precision an order of magnitude greater than possible elsewhere.

The ASGAT project, with a grant of FF2 million $(£ 200,000)$ from the CEA and INSU, will run for three years initially. Four mirrors will be installed by November 1987 and the remaining three by mid1988. Goret hopes, eventually, for a Europe-wide collaboration to enlarge the observatory, with double the number of mirrors.
Peter Coles

\section{Taking science to the Indian masses}

New Delhi

Twenty-six People's Science Organisations (PSOs), backed by hundreds of scientists, plan to cover $25,000 \mathrm{~km}$ of India by road to share with people the excitement of science and to explain how it can change their lives.

Preparations have already begun for the month-long All-India Science Festival beginning in October. Starting from five different towns, the PSO buses will stop at 500 places. The messages of science will be spread by roadside dramas, songs, films, quizzes, essay competitions and models.

The marathon science march will end on 7 November when 1,000 scientists and 5,000 teachers will join the PSOs in a daylong science 'Woodstock' at Bhopal. Two dozen institutions are associated with the development of exhibits.

Eighty per cent of Indians live in villages where the impact of modern science and technology is not visible. According to its organizers, the festival seeks to "forge active grass-root linkages between scientists and the people at large who are presently alienated from science". The festival should reach 5 million people directly and 50 million indirectly. K.S.Jayaraman

was needed to extend the lifespans of ageing gas-cooled 'Magnox' reactors (the uranium fuel bars are contained in magnesium alloy - 'Magnox' - cans). Of the 26 Magnox reactors built between 1956 and 1971,11 are still in use.

According to engineering data available at the time of their conception, the reactors were expected to have safe lives of 20-25 years. As a condition of extending the lifespans of the Magnox stations, the government's safety watchdog, the Nuclear Installations Inspectorate (NII), ordered CEGB to carry out a five-year long-term safety review of each reactor. Last week, NII published its assessment of the first review, for the two-reactor station at Bradwell, in Essex, built in 1962 and Britain's oldest nuclear power station.

Although NII accepts that there is no evidence to suggest immediate danger from the station, it lists 17 key requirements that must be met if the station is to continue in operation until 1992. The most serious questions concern weaknesses in the pressure circuits that contain the pressure vessels housing the nuclear core.

CEGB have until October to convince NII that it can meet the requirements, the work for which must be carried out to NII's satisfaction by March 1989. If not, NII will call for the reactor pressure to be lessened, making the station uneconomic to run. CEGB is confident that it can meet the deadlines at a cost of between $£ 3$ and $£ 5$ million. 